\title{
Pisa syndrome induced by switching of a choline-esterase inhibitor treatment from donepezil to galantamine: a case report
}

\author{
Yu Mimura ${ }^{1,2^{*}}$ D, Shin Kurose ${ }^{1,2}$, Taketo Takata' ${ }^{1}$, Hajime Tabuchi $^{2}$, Masaru Mimura ${ }^{2}$ and Michitaka Funayama ${ }^{1}$
}

\begin{abstract}
Background: Pisa syndrome (PS) is characterized by an abnormally sustained posture, with flexion of the body and head to one side and slight rotation of the trunk. Although PS most commonly arises as an adverse effect of antipsychotic drugs, choline-esterase inhibitors (ChEls) are also sometimes known to induce PS. Despite the fact that the precise mechanism remains unclear, cholinergic-dopaminergic imbalance has been considered as a possible pathophysiologic mechanism underlying the genesis of PS.

Case presentation: We hereby report the case of a 60-year-old woman with Alzheimer's disease who presented with the signs of PS after her treatment was switched to galantamine, a type of ChEl, even though she had received donepezil, another type of ChEl, for 5 years without any complications. To the best of our knowledge, this is the first report of PS associated with treatment switch from one to another type of ChEl. Galantamine, but not other ChEls, can enhance striatal dopamine release through allosteric modulation of the nicotinic acetylcholine receptor, and has weaker muscarinic effects than donepezil. Therefore, we propose two novel hypotheses to explain the development of PS, as follows; galantamine, which enhances dopamine release, can induce imbalance of dopamine levels in the striatum of patients with dementia, resulting in PS, and the weaker muscarinic effects of the drug could be one of the factors predisposing to the development of PS.
\end{abstract}

Conclusion: The present case suggests that treatment with galantamine is associated with a higher risk of development of PS than that with other ChEls, such as donepezil, despite the pharmacological profile of galantamine as a dopamine modulator. Also, this report provides novel insight into another plausible mechanism underlying the development of PS, besides cholinergic-dopaminergic imbalance, namely, dopamine imbalance in the striatum with muscarinic-nicotinic imbalance.

Keywords: Pisa syndrome, Choline-esterase inhibitor, Galantamine, Dopamine, Nicotinic effects, Extra-pyramidal symptom, Alzheimer's disease

\footnotetext{
* Correspondence: yu.mimura@keio.jp

'Department of Neuropsychiatry, Japanese Red Cross Ashikaga Hospital, 49-1

Yobe, Ashikaga, Tochigi, Japan

${ }^{2}$ Department of Neuropsychiatry, Keio University School of Medicine, 35

Shinanomachi, Shinjuku, Tokyo, Japan
}

(C) The Author(s). 2020 Open Access This article is licensed under a Creative Commons Attribution 4.0 International License, which permits use, sharing, adaptation, distribution and reproduction in any medium or format, as long as you give appropriate credit to the original author(s) and the source, provide a link to the Creative Commons licence, and indicate if changes were made. The images or other third party material in this article are included in the article's Creative Commons licence, unless indicated otherwise in a credit line to the material. If material is not included in the article's Creative Commons licence and your intended use is not permitted by statutory regulation or exceeds the permitted use, you will need to obtain permission directly from the copyright holder. To view a copy of this licence, visit http://creativecommons.org/licenses/by/4.0/ The Creative Commons Public Domain Dedication waiver (http://creativecommons.org/publicdomain/zero/1.0/) applies to the data made available in this article, unless otherwise stated in a credit line to the data. 


\section{Background}

Pisa syndrome (PS) or pleurothotonus, is characterized by a marked lateral trunk flexion that can be reduced by passive mobilization or supine positioning [1], and was originally described by Ekbom in 1972 [2]. PS is observed in patients with neurodegenerative diseases, mainly Parkinson's disease [3]. PS is also considered as one of the rare types of tardive dystonias caused by drugs such as choline-esterase inhibitors (ChEIs) [4-18], antipsychotics [19-21], antidepressants [22, 23], lithium [24], and valproic acid [25]. However, the precise pathophysiology of PS has not yet been established. PS induced by ChEIs and antipsychotics has been assumed to be induced by cholinergic-dopaminergic imbalance. In other words, antipsychotics can decrease dopaminergic neurotransmission, and ChEIs can increase both the levels and actions of acetylcholine in the synaptic clefts to cause choline-dominance imbalance [3, 11, 17]. Decrease of dopaminergic functions with enhanced cholinergic functions cause the tonic influence on posture and locomotion to change toward the direction of immobility, because cholinergic-dopaminergic balance in the nigrostriatal neuronal system maintains normal muscle tone in the human body [26]. Disruption of the cholinergic-dopaminergic balance could result in an asymmetric axial muscle tone activation, and this is the hypothesized pathogenic mechanism underlying the development of drug-induced PS. Herein, we present the case report of a patient who presented with signs of PS following switching of ChEI treatment from donepezil to galantamine. Our case might shed some light on the onset of PS induced by ChEIs.

\section{Case presentation}

A 57-year-old Japanese woman visited the memory clinic affiliated to our hospital with a 2-year history of visual memory loss. Examination revealed that the patient had agraphia as well as left-right agnosia. Her insights into her cognitive dysfunction, however, were relatively wellpreserved. She showed no signs of parkinsonism. Magnetic resonance imaging and single- photon emission computed tomography of the head revealed bilaterally symmetric atrophy of the occipitoparietal lobes and decreased blood flow to the same areas. She was clinically diagnosed as having posterior cortical atrophy, a visual variant of early-onset Alzheimer's disease.

She was prescribed donepezil at the dose of $3 \mathrm{mg}$ per day, which was later increased to $10 \mathrm{mg}$ per day, in the absence of any side effects. Her visuospatial function gradually deteriorated during the treatment. In the following year, she presented with dressing apraxia. At the age of 60, she had difficulty in positioning herself to sit on a chair; her attempts to take a seat often resulted in her missing the chair and she found herself trying to sit on air instead. She was unable to find her way out of our examination room. She became dependent for her activities of daily living. She also became so impulsive and agitated that she was always talking to herself, without daily fluctuations in cognitive functions. Donepezil was discontinued in view of her agitation. Instead, she was started on augmentation therapy with the combination of galantamine and memantine to improve her psychiatric symptoms and maintain her cognitive function status. However, two weeks after the treatment switch from donepezil to galantamine plus memantine, she was admitted to the neuropsychiatric unit of our hospital, because her psychiatric symptoms did not improve, and she began to show signs of parkinsonism.

On admission, she presented with frozen gait and a mask-like expression. No rigidity, tremor or other neurological signs, such as paralysis or sensory impairment, were apparent. There were no remarkable changes of the vital signs or abnormalities on physical and laboratory examinations. Cerebrospinal fluid (CSF) examination revealed no increase of the cell count or protein levels, and the IgG index was within normal limits. The CSF amyloid beta 1-42(A $\beta$ 1-42) level was $116 \mathrm{pg} / \mathrm{mL}$ and that of phosphorylated tau(P-tau) was $41 \mathrm{pg} / \mathrm{mL}$, consistent with the diagnosis of Alzheimer's disease [27]. To examine the possibility of Lewy body disease, ${ }^{123} \mathrm{I}$ (3meta)-iodobenzylguanidine myocardial scintigraphy and dopamine-transporter scanning were performed, which showed early and delayed heart/mediastinum ratios of 3.96 and 3.88, and specific binding ratios of 5.76 (right) and 5.78 (left), respectively, excluding Lewy body disease. Also, corticobasal syndrome was ruled out, because of the absence of laterality.

Her medications on admission included galantamine 4 mg bid, memantine $10 \mathrm{mg}$ qd, suvorexant $20 \mathrm{mg}$ qd. Her parkinsonism signs deteriorated after she was hospitalized. In particular, she showed sustained flexion of both the head and body trunk, with slight rotation of the body to the right side, consistent with the diagnosis of PS, which was exacerbated while walking; these symptoms remained fixed until the 13th hospital day. Based on the suspicion that the PS in this patient had developed as a side effect of galantamine, this drug was stopped on the 13th hospital day. After discontinuation of galantamine while continuing memantine monotherapy, the characteristic posture of PS gradually improved within 2-3 days. In accordance with improvements on posturing, her freezing of gait also disappeared so that she was able to walk without any assistance. Meanwhile, her masked face was preserved. Finally, her posturing almost thoroughly disappeared over the subsequent 14-day period (Fig. 1).

For the agitation and insomnia, the patient was prescribed $5 \mathrm{mg}$ of asenapine, an antipsychotic, which was 


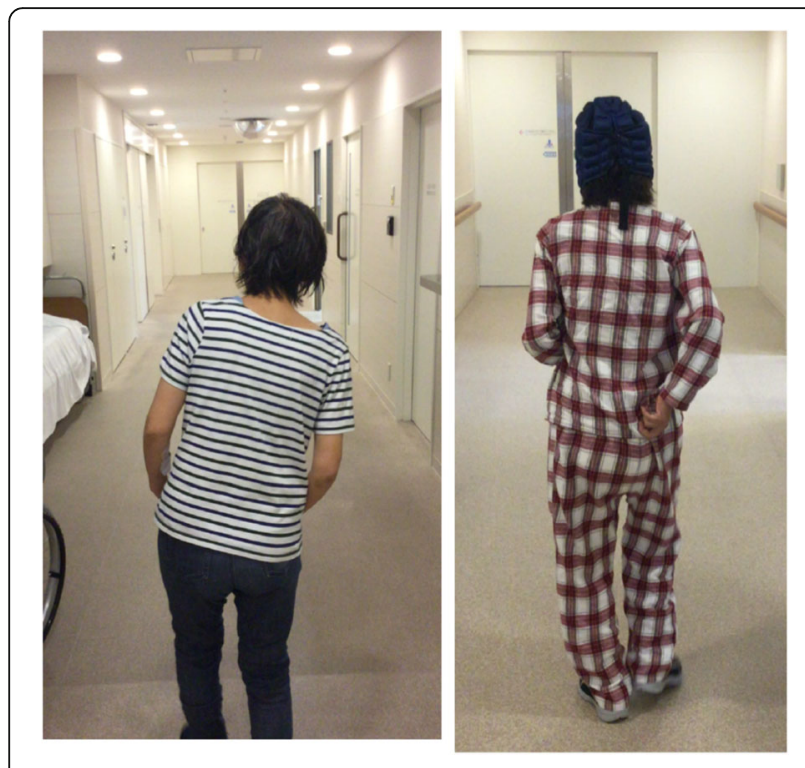

Fig. 1 Left: Sustained flexion of both head and body trunk, with slight rotation of the body to right side. Right: 14 days after discontinuation of galantamine while continuing memantine therapy, the characteristic posture of Pisa syndrome disappeared effective without any side effects in terms of extrapyramidal symptoms (EPS), including PS. By the 93rd hospital day, her neuropsychiatric symptoms had markedly improved and the patient was discharged home, where she was taken care of by her family members in her daily life.

\section{Discussion and conclusion}

To the best of our knowledge, this is the first case report of PS induced by a treatment switch of a ChEI to galantamine, despite prior long-term use, for 5 years, of donepezil without any complications. As for PS induced by ChEIs, a large pharmacovigilance study reported 52 cases of PS [28]. According to the previous report, PS occurs most frequently with galantamine, followed by rivastigmine and donepezil [28]. Our case report on PS is consistent with their findings. We reviewed and summarized all case reports that described PS linked to ChEIs initiation in Table 1.

The mechanisms underlying the development of PS are not yet fully understood. Many past reports have suggested that cholinergic-dopaminergic balance in the direction of cholinergic dominance is the main cause of PS [3]. This hypothesis is widely accepted and based on the fact that the symptoms most often develop with the use of antipsychotics and ChEIs, and improve with the use of anticholinergics [3].

Table 1 All previous case reports that described PS linked to ChEls initiation in Table 1

\begin{tabular}{|c|c|c|c|c|c|c|c|c|c|}
\hline Author/Year/Reference No. & Age & Sex & Diagnosis & $\begin{array}{l}\text { General cognitive } \\
\text { function }\end{array}$ & $\begin{array}{l}\text { ChE-I being used when } \\
\text { PS started }\end{array}$ & Other medications & $\begin{array}{l}\text { Duration of onset from } \\
\text { ChE-I initiation }\end{array}$ & $\begin{array}{l}\text { Duration of improvement } \\
\text { from ChE-I discontinuation }\end{array}$ & Other treatments \\
\hline \multirow{2}{*}{ Kwak et al., $2000[4]$} & 53 & $\mathrm{~F}$ & $A D$ & NA & $\begin{array}{c}\text { Donepezil 5mg } \\
\text { Rivastigmine } 9 \mathrm{mg}\end{array}$ & Risperidone $1 \mathrm{mg}$ & $\begin{array}{c}4 \text { weeks for donepezil } \\
7 \text { weeks for rivastigmine }\end{array}$ & $\begin{array}{l}7 \text { days for donepezil } \\
7 \text { days for rivastigmine }\end{array}$ & None \\
\hline & 73 & $\mathrm{~F}$ & $A D$ & NA & $\begin{array}{c}\text { Donepezil 5mg } \\
\text { Rivastigmine 3mg }\end{array}$ & Risperidone $1 \mathrm{mg}$ & $\begin{array}{l}16 \text { weeks for donepezil } \\
10 \text { days for rivastigmine }\end{array}$ & $\begin{array}{c}8 \text { weeks for donepezil } \\
3 \text { weeks for rivastigmine }\end{array}$ & None \\
\hline Miyaoka et al., 2001 [13] & 57 & M & $A D$ & MMSE $15 / 30$ & Donepezil $5 \mathrm{mg}$ & None & 4 weeks & 7 days & None \\
\hline \multirow[t]{2}{*}{ Villarejo et al., 2003[14] } & 77 & $\mathrm{~F}$ & AD & NA & Donepezil 10mg & Risperidone $1 \mathrm{mg}$ & 4 weeks & NA & $\begin{array}{l}\text { Biperiden IV: unresponse } \\
\text { Risperidone discontinuation: response } \\
\text { within } 6 \text { days }\end{array}$ \\
\hline & 72 & $\mathrm{~F}$ & PD & MMSE 23 & Donepezil 5mg & Levodopa $800 \mathrm{mg}$ Pergolide $2 \mathrm{mg}$ & 2 months & 10 days & None \\
\hline Cossu et al., 2004 [12] & 72 & $\mathrm{~F}$ & $A D$ & MMSE $21 / 30$ & Galanatmine $8 \mathrm{mg}$ & None & 4 weeks & Not improved & $\begin{array}{c}\text { Botulinum toxin type-A: response within } 3 \\
\text { months }\end{array}$ \\
\hline \multirow{5}{*}{ Huvent-Grelle et al., 2007 [15] } & 78 & $\mathrm{~F}$ & $A D$ & MMSE $16 / 30$ & Galantamine & None & 11 months & 15 days & None \\
\hline & 75 & $\mathrm{~F}$ & $A D$ & MMSE 21/30 & Donepezil & Atypical antipsychotics & 4 years & 15 days & None \\
\hline & 72 & $\mathrm{~F}$ & $A D$ & NA & Galantamine & Atypical antipsychotics & 6 months & NA & Switching to rivastigmine \\
\hline & 76 & $\mathrm{~F}$ & AD & $\mathrm{NA}$ & Donepezil & Atypical antipsychotics & 12 months & Partial resolution & None \\
\hline & 79 & M & AD & MMSE $12 / 30$ & Rivastigmine & None & 24 months & NA & None \\
\hline Chen et al., 2008 [5] & 65 & $\mathrm{~F}$ & AD & NA & Galanatmine $16 \mathrm{mg}$ & $\begin{array}{c}\text { Sertraline } 50 \mathrm{mg} \\
\text { Valproic acid } 500 \mathrm{mg}\end{array}$ & 6 month & Not improved & Switching to memantine monotherapy \\
\hline \multirow{2}{*}{ Huvent-Grelle et al., 2009[16] } & 98 & $\mathrm{M}$ & $A D$ & MMSE $19 / 30$ & Donepezil & None & 3 months & 7 days & None \\
\hline & 80 & M & AD & MMSE $11 / 30$ & Donepezil & None & 18 months & NA & None \\
\hline Shinfuku et al., 2011[11] & 71 & $\mathrm{~F}$ & DLB & $\begin{array}{l}\text { HDS-R 22/30 } \\
\text { WAIS FIQ } 65\end{array}$ & Donepezil $5 \mathrm{mg}$ & None & 12 months & Not improved & None \\
\hline Leelavathi., $2012[17]$ & 80 & $\mathrm{M}$ & $A D$ & MMSE $11 / 30$ & Rivastigmine & $\mathrm{NA}$ & 18 months & NA & Switching to donepezil \\
\hline Panagiotis et al., 2012 [10] & 74 & $\mathrm{~F}$ & $A D$ & MMSE $18 / 30$ & Donepezil & None & a few hours & 8 days & None \\
\hline \multirow{3}{*}{ Vanacore et al., 2013[6] } & 83 & $\mathrm{~F}$ & $A D$ & MMSE $14 / 30$ & Donepezil 5mg & Thioridazine $25 \mathrm{mg}$ & 1 month & 16 days & None \\
\hline & 84 & $\mathrm{~F}$ & $A D$ & MMSE $9 / 30$ & $\begin{aligned} & \text { Donpezile } 5 \mathrm{mg} \\
& \rightarrow \text { Donepezil } 10 \mathrm{mg} \\
& \rightarrow \text { Donepezil } 5 \mathrm{mg} \\
&\end{aligned}$ & None & 4 months & 7 days & Switching to rivastigmine: unresponse \\
\hline & 75 & $\mathrm{~F}$ & $A D$ & MMSE $10 / 30$ & $\begin{array}{c}\text { Donepezil 10mg } \\
\rightarrow \text { Donepezil } 5 \mathrm{mg}\end{array}$ & Citalopram $20 \mathrm{mg}$ & 2.5 years & 14 days & $\begin{array}{l}\text { Switching to rivastigmine: response within } \\
14 \text { days }\end{array}$ \\
\hline Hsu et al., 2017 [8] & 57 & $\mathrm{~F}$ & $A D$ & CDR 1 & Rivastigmine 3mg-9mg & None & 19 months & 1 month & None \\
\hline Pollock et al., 2017 [9] & 87 & M & AD & NA & Donepezil 10mg & $\begin{array}{l}\text { Citalopram } 10 \mathrm{mg} \\
\text { Lamotrigine } 25 \mathrm{mg}\end{array}$ & 24 months $<$ & 3 months & None \\
\hline Chao et al., 2018 [7] & 67 & $\mathrm{~F}$ & $\begin{array}{c}\text { AD/Schizo } \\
\text { phrenia }\end{array}$ & MMSE 20/30 & Rivastigmine $1.5 \mathrm{mg}$ & Clozapine $150 \mathrm{mg}$ & 5 days & 7 days & None \\
\hline Mukku et al., 2018 [18] & 60 & M & $\begin{array}{c}\text { Mixed } \\
\text { dementia } \\
\text { (AD and } \\
\text { TBI) }\end{array}$ & NA & Donepezil $10 \mathrm{mg}$ & Quetiapine $100 \mathrm{mg}$ & 3 month $<$ & 3 days & $\begin{array}{l}\text { Promethazine } 25 \mathrm{mg} \text { IM: partial response } \\
\text { Clonazepam } 1 \mathrm{mg} \text { : unresoponse }\end{array}$ \\
\hline
\end{tabular}


However, the notion that galantamine, among the ChEIs is associated with the highest risk of development of PS is inconsistent with the results of a recent animal study on the effects of galantamine. Galantamine is not only a ChEI, but also an allosteric potentiating ligand (APL) for the nicotinic acetylcholine receptor. In experiments conducted using a hemiparkinsonian rat model, galantamine was found to facilitate striatal dopamine release by acting as an APL at the $\alpha 4$ nicotinic acetylcholine receptor [29]. This seems to be inconsistent with galantamine as a risk factor for PS, because EPS are primarily caused by blockade of the dopamine D2 receptor. On the other hand, in the experiment conducted by Inden et al., both methamphetamine, which enhances dopamine release, and the combination of a dopamine reuptake inhibitor plus galantamine induced the same rotational behavior, indicating that galantamine enhances dopamine release on the contralateral side of the striatum in the hemiparkinsonian model of rats [29]. From this point of view, dopamine imbalance triggered by galantamine in the striatum would induce rotation and flexion of the body to one side like PS. In our presented case, even though the dopamine transporter scan was negative, this imbalance might become worse by dopamine release induced on one side by galantamine.

In another mouse study conducted by Shimizu et al., the results were consistent with galantamine as a strong risk factor for PS [30]. According to this study on the effects of donepezil-, galantamine-, and antipsychotic drug-induced EPS, galantamine induced and augmented EPS more potently than donepezil [30]. In this experiment, EPS induced by galantamine was completely ameliorated by a muscarinic antagonist, but not by a nicotinic antagonist, suggesting that ChEI-induced EPS primary involves muscarinic effects and is improved by muscarinic antagonists. In addition, galantamine has a weaker antagonistic effect against the muscarinic receptor as compared to donepezil [31]. Taken together, weaker effect on the muscarinic receptors is associated with an increase in the risk of development of EPS.

In our case, memantine was the better alternative, because the patient showed good tolerability to memantine. In order to not only maintain the patient's cognitive functions, but also to resolve the symptoms, memantine, which acts by non-competitive binding to the $\mathrm{N}$-methyl-D-aspartate (NMDA) receptor, is an effective, reasonable, and safe treatment agent [5]. In fact, mouse experiments support this notion, in that memantine significantly reduced EPS induced by haloperidol, as compared to galantamine and donepezil, through its antagonistic effect on the NMDA receptor [32].

In addition to switching ChEIs, the patient's impaired visuo-spatial function might be related to PS in the presented case. According to previous reports, visuo-spatial dysfunction assessed by Benton's judgement line orientation test was a strong and significant predictor for developing PS [33, 34]. Given the abnormal posture in PS, however, disruption in body schema, rather than visuospatial dysfunction, might influence the development of PS because the main atrophic area involved the bilateral parietal lobe, which is considered the neural basis for body schema [35]. Still, switching was a major cause because posturing was completely resolved after discontinuation of galantamine.

This case report has some limitations. First of all, no electromyography was performed, because we were not sure whether we could perform the examinations safely. Also, there is a possibility that the symptoms represented delayed effects of donepezil in our case. However, we are reasonably certain about our diagnosis based on the fact that our patient presented with the symptoms of PS soon after ( 2 weeks later) her treatment was switched to galantamine and her symptoms disappeared soon after ( 2 weeks later) galantamine was discontinued. The Naranjo score of 5 indicates that galantamine was the probable cause of PS in our case [36]. Additionally, to the best of our knowledge, the longest period between the initiation of ChEI treatment and the onset of PS is 24 months [14]. Finally, a major limitation is that this was just a single case report. Further cases should be collected to better understand the pathophysiology of PS.

In conclusion, we present the first case report of PS that developed soon after the patient's treatment was switched to galantamine from donepezil, even though the patient had shown good tolerability to $10 \mathrm{mg}$ of donepezil for 5 years. This case suggests additional possible mechanisms underlying the development of PS, besides the conventional cholinergic-dopaminergic imbalance theory, including dopamine imbalance in the striatal system and muscarine-nicotine imbalance.

\section{Abbreviations}

PS: Pisa syndrome; ChEls: Choline-esterase inhibitors; CSF: Cerebrospinal fluid: APL: Allosteric potentiating ligand; EPS: Extrapyramidal symptoms; NMDA: NMethyl-D-Aspartate; M: Male; F: Female; AD: Alzheimer's disease;

PD: Parkinson's disease; DLB: Dementia with Lewy body; TBI: Traumatic brain injury; NA: Not available; HDS-R: Hasegawa Dementia Scale Revised; WAIS: Wechsler adult intelligence scale; FIQ: Full scale intelligence quotient; CDR: Clinical dementia rating

\section{Acknowledgments}

None.

\section{Authors' contributions}

YM acquired case data and drafted the manuscript. MF, SK, and TT acquired case data. MF, HT, and MM supervised the study and substantively revised the manuscript. All authors read and approved the final manuscript.

Funding

Not applicable.

Availability of data and materials

All data generated or analysed during this study are included in this published article and its supplementary information files. 


\section{Ethics approval and consent to participate}

Not applicable.

\section{Consent for publication}

Written informed consent was obtained from family member of the patient for publication of this report and any accompanying images. A copy of the written consent is available for review by the Editor of this journal.

\section{Competing interests}

The authors declare that they have no competing interests.

Received: 3 January 2020 Accepted: 6 May 2020

Published online: 13 May 2020

\section{References}

1. Doherty KM, Van De Warrenburg BP, Peralta MC, Silveira-moriyama L, Azulay J, Gershanik OS. Postural deformities in Parkinson's disease. Lancet Neurol. 2011;10:538-49.

2. Ekbom K, Lindholm H, Ljungberg L. New dystonic syndrome associated with butyrophenone therapy. Z Neurol. 1972;202:94-103.

3. Suzuki T, Matsuzaka H. Drug-induced Pisa syndrome (Pleurothotonus). CNS Drugs. 2002;16:165-74

4. Kwak YT, Han IIW, Baik J, Koo MS. Relation between cholinesterase inhibitor and Pisa syndrome. Lancet. 2000;355:2222.

5. Chen CF, Hsu HC, Ouyang WC, Lin YC. Galantamine-induced pisa syndrome: Memantine as an alternative. Int J Geriatr Psychiatry. 2008:23:660-1.

6. Vanacore N, Suzzareddu G, Maggini M, Casula A, Capelli P, Raschetti R. Pisa syndrome in a cohort of Alzheimer's disease patients. Acta Neurol Scand. 2005:111:199-201.

7. Chao PC, Li JC, Yeh TC, Bin YC. A very low dose of rivastigmine-induced Pisa syndrome in a clozapine-treated patient. Aust N Z J Psychiatry. 2018:52:204-5.

8. Hsu CW, Lee Y, Lee CY, Lin PY. Reversible Pisa syndrome induced by rivastigmine in a patient with early-onset Alzheimer disease. Clin Neuropharmacol. 2017;40:147-8.

9. Pollock D, Cunningham E, Mcguinness B, Passmore AP. Pisa syndrome due to donepezil: pharmacokinetic interactions to blame? Age Ageing. 2017;46: 529-30.

10. Panagiotis I, Pantelis M, George B, Dimitris K. Acute Pisa syndrome after administration of a single dose of donepezil. J Neuropsychiatry Clin Neurosci. 2012;24:2012

11. Shinfuku M, Nakajima S, Uchida H, Watanabe K, Kocha H, Kashima H. Pisa syndrome caused by an acetylcholinesterase inhibitor in a patient with dementia with Lewy bodies. Psychiatry Clin Neurosci. 2011;65:299.

12. Cossu G, Melis M, Melis G, Maccioni E, Putzu V, Catte O, et al. Reversible Pisa syndrome (Pleurothotonus) due to the cholinesterase inhibitor galantamine: case report. Mov Disord. 2004;19:1243-4.

13. Miyaoka T, Seno H, Yamamori C, Inagaki T, Itoga M, Tsubouchi KHJ. Pisa syndrome due to a cholinesterase inhibitor (donepezil): a case report. J Clin Psychiatry. 2001;62:573-4.

14. Villarejo A, Camacho A, Garcia-Ramos R, Moreno T, Penas M, Juntas R, et al. Case report: cholinergic-dopaminergic imbalance in Pisa syndrome. Clin Neuropharmacol. 2003;26:119-21.

15. Huvent-Grelle D, Roche J, Camus FE, Dewailly PH, Puisieux F. Relation between cholinesterase inhibitors and Pisa syndrome in a cohort of five French patients with Alzheimer's disease. JAGS. 2007:55:1472-87.

16. Huvent-Grelle D, Roche J, Gaxatte C, Dewailly P, Puisieux F. Relation between Pisa syndrome and choline esterase inhibitors in a cohort of Alzheimer's disease patients. Presse Med. 2009;38(1):150-3.

17. Leelavathi $M$, Rosdinom $R$, Suguna M. Pisa syndrome secondary to rivastigmine: a case report. Clin Ter. 2012;163:31-2.

18. Mukku SSR, Achary U, Sivakumar PT, Varghese M. Reccurent truncal dystonia (Pisa syndrome) due to donepezil — A case report. Asian J Psychiatr. 2018, 35:47-9.

19. Kumar RNS, Gopalakrishnan A. Clozapine-associated Pisa syndrome: a rare type of tardive dystonia. Indian J Psychiatry 2017; 59: 390-391.

20. Faridhosseini F, Omidi-Kashani F, Baradaran A. Pisa syndrome associated with clozapine: a rare case report and literature review. Spine Deform. 2015; 3:386-9.

21. Yassa R, Nastase C, Cvejic J, Laberge G. The Pisa syndrome (or pleurothotonus): prevalence in a psychogeriatric population. Biol Psychiatry. 1991;29:942-5.
22. Yamada Y, Takano H, Yamada M, Satake N, Hirabayashi N, Okazaki M, et al Pisa syndrome associated with mirtazapine: a case report. BMC Pharmaco Toxicol. 2018;19:18-20

23. Perrone V, Antoniazzi S, Carnovale C, Clementi E, Radice S, Ba G, et al. A case of Pisa syndrome during sertraline and Quetiapine treatment. J Neuropsychiatry Clin Neurosci. 2012;24:31-2.

24. Kumar N, Mendonça DA, Jog M. Teaching video Neuro images: Lithiuminduced reversible Pisa syndrome. Neurology. 2017;88:e184.

25. Yohanan M, Aulakh JS, Weith J, Hawkins JW. Pisa syndrome in a patient in a wheelchair taking Valproic acid. Am J Psychiatry. 2006;163:325.

26. Duvoisin RC, Marsden CD. Note on the scoliosis of parkinsonism. J Neurol Neurosurg Psychiatry. 1975;38:787-93

27. Tapiola T, Alafuzoff I, Herukka SK, Parkkinen L, Hartikainen P, Soininen H, et al. Cerebrospinal fluid $\beta$-amyloid 42 and tau proteins as biomarkers of Alzheimertype pathologic changes in the brain. Arch Neurol. 2009;66:382-9.

28. Zannas AS, Okuno Y, Doraiswamy PM. Cholinesterase inhibitors and Pisa syndrome: a pharmacovigilance study. Pharmacotherapy. 2014;34:272-8.

29. Inden M, Takata K, Yanagisawa D, Ashihara E, Tooyama I, Shimohama S, et al. A4 nicotinic acetylcholine receptor modulated by Galantamine on Nigrostriatal terminals regulates dopamine receptor-mediated rotational behavior. Neurochem Int. 2016;94:74-81.

30. Shimizu S, Mizuguchi Y, Sobue A, Fujiwara M, Morimoto T, Ohno Y. Interaction between anti-Alzheimer and antipsychotic drugs in modulating extrapyramidal motor disorders in mice. J Pharmacol Sci. 2015:127:439-45.

31. Ago Y, Koda K, Ota Y, Kita Y, Fukada A, Takuma K, et al. Donepezil, but not galantamine, blocks muscarinic receptor-mediated in vitro and in vivo responses. Synapse. 2011;65:1373-7.

32. Ohno Y, Kunisawa N, Shimizu S. Antipsychotic treatment of behavioral and psychological symptoms of dementia (BPSD): Management of extrapyramidal side effects. Front Pharmacol. 2019;10 SEP:1-10.

33. Vi tale C, Falco F, Trojano L, Erro R, Moccia M, Allocca R, et al. Neuropsychological correlates of Pisa syndrome in patients with Parkinson's disease. Acta Neurol Scand. 2016;101-7.

34. Artusi CA, Montanaro E, Tuttobene S, Romagnolo A, Zibetti M, Lopiano L. Pisa Syndrome in Parkinson's Disease Is Associated with Specific Cognitive Alterations; 2019. p. 1-7.

35. Wong B, Lucente DE, Maclean J, Padmanabhan J, Brandt KD, Putcha D, et al. Diagnostic evaluation and monitoring of patients with posterior cortical atrophy. 2019; December 2018.

36. Naranjo CA, Busto U, Sellers EM, Sandor P, Ruiz I, Roberts EA, et al. A method for estimating the probability of adverse drug reactions. Clin Pharmacol Ther 1981:30:239-45.

\section{Publisher's Note}

Springer Nature remains neutral with regard to jurisdictional claims in published maps and institutional affiliations.
Ready to submit your research? Choose BMC and benefit from:

- fast, convenient online submission

- thorough peer review by experienced researchers in your field

- rapid publication on acceptance

- support for research data, including large and complex data types

- gold Open Access which fosters wider collaboration and increased citations

- maximum visibility for your research: over $100 \mathrm{M}$ website views per year

At BMC, research is always in progress.

Learn more biomedcentral.com/submissions 